\title{
Inhalt des 31. Bandes
}

\section{Number 1}

K. H. Finken: Untersuchungen an dichten z-Pinch-Plasmen . . . . . . . . . . 1

\section{Number 2}

F. M. Lev: On a Three-Body Problem in Relativistic Quantum Mechanics . . . . . . . . 75

\section{Number 3}

S. K. Bose and D. N. Tripathy: Studies of Coupled Anharmonic Oscillator Problem Using Coherent States and Path Integral Approaches . . . . . . . . . . . . . . 131

H. Stöok RiL: Linear and Nonlinear Generalizations of Onsager's Reciprocity Relations. Treatment of an Example of Chemical Reaction Kinetics . . . . . . . . . . . . . . 165

\section{Number 4}

R. N. Mohapatra: Left-Right Symmetry, Grand Unification and Cosmology . . . . . . . 185

\section{Number 5}

B. G. Konopelonenko: Nonlinear Transformations and Integrable Evolution Equations . . 253

H. Genz, and S. Martik: Tensor Meson Dominance and $\theta^{+} e^{-}$Physics . . . . . . . . . 297

\section{Number 6}

B. MrEEWSEI: Four Dimensional Theories with Composite Gauge Fields and Their Supersymmetric Generalizations . . . . . . . . . . . . . . . . . . 313

J. KUPSCH: Strong Coupling Problems of $S$-Matrix Equations . . . . . . . . 339

\section{Number 7}

H. ScHEIDT: Neuere Entwicklungen auf dem Gebiet der Bremsstrahlungs-Isochromatenspektroskopie . . . . . . . . . . . . . . . . . . . 357

M. H. ZAIDr: Functional Methods . . . . . . . . . . . . . . . . . . . . . . . . . . . . . . 403

\section{Number 8-9}

L. M. Soroko: Nuclear Magnetic Resonance Imaging and Related Topics . . . . . . . 419 


\section{Number 10}

Y. TAKAHASHI, and K. OKUDA: A Spinorization of a Constrained Vector System and a Spinor

Reconstruction Theorem . . . . . . . . . . . . . . . . . 511

B. M. Barbashov, and V. V. Nesterenko: Continuous Symmetries in Field Theory . . . . 535

\section{Number 11}

V. SrvaH: Grand Unification and the Big-Bang Cosmology . . . . . . . . . . . . . . . 569

O. K. Kalashnikov: Experimental Consequences of the Asymptotically Free $S U(5)$-Model 591

o. K. Kalashirtzov, V. V. Krmmov, and E. Casado: The Non-Perturbative Approach to the Infrared Problem in QCD at Finite Temperature . . . . . . . . . . . . .613

\section{Number 12}

V. I. Yukacov, and V. I. Zubov: Localized-Particles Approach for Classical and Quantum Crystals .......................627 